\title{
Research of Kindergarten Financial Management Strategy Based on ERP
}

\section{Environment}

\author{
Lina Cheng ${ }^{1}$ \\ ${ }^{1}$ Department of Political Economy, Shaanxi Xueqian Normal University, Xi'an, 710100 \\ 346591653@163.com
}

KEYWORDS: ERP; Financial Management; Kindergarten

\begin{abstract}
For management of kindergarten enterprise resource management this stage, ERP has a very significant meaning. It can help the kindergarten to better manage their resource plan for immediate and foreseeable future resource needs, reduce management costs and improve management efficiency. However, due to the use of ERP in kindergarten range is still small, the use of time is not long, kindergarten in the ERP is on the process, especially use ERP financial management to conduct kindergarten financial management will inevitably encounter many problems, it is necessary to strengthen ERP study risk control, internal control, comprehensive budget management issues, so that ERP can play a greater role in the financial management of the kindergarten.
\end{abstract}

\section{Introduction}

ERP (Enterprise Resource Planning) refers to as the popularity of the rapid development of modern information technology, and advanced management theory, enterprises optimize the allocation of the ordinary course of business information flow, logistics and cash flow, increase its use efficiency, and provide a comprehensive data management platform and operational means for business decision-makers and staff. Moreover, ERP will be customer demand, production and supplier of resources for effective integration, which enables enterprises to effectively control all aspects of the supply chain, in order to achieve the overall management. With the increasing degree of social information, ERP has become an important means of managing today's enterprise.

\section{Kindergarten Insufficient Presence of Financial Management}

A. Less Understanding of the ERP System

When the ERP system is under construction, kindergarten ERP system to focus on the flow of information architecture, and logistics control remains weak. In addition, the kindergarten's leadership has not been fully aware of the importance of ERP, ERP system to participate in the process of building enthusiasm is low, when faced with problems, did not realize the importance of consultation, leading to failure to select the optimal the most appropriate solution, and the failure to solve the problem in a timely manner.

\section{B. Low Quality of Personnel in the Financial Management}

On ERP system construction process, the quality of financial personnel directly determines the success or failure of the system construction. The financial information provided by the finance 
staff is the key to business decisions based on kindergarten, we must ensure real and effective, authenticity, and financial officers on when to take up the role of a leading role in this information. The quality of financial personnel kindergarten is still low, have not been operating ERP systems training system, not yet proficient in the use of ERP financial controls, decision-making and strategic management system to operate, so that the efficiency and effectiveness of the final low.

\section{Kindergarten ERP System does not Match Actual Requirements of Financial Management}

Although kindergarten used to be expensive and advanced ERP system, but because of management and profit analysis kindergarten is still in a semi-automated stage, and failed to take advantage of the computer, which leads to a comprehensive ERP system fails to collect electronic data for analysis.

\section{Multiple Conflicts in ERP Implementation Process}

Kindergarten carried out in the course of a comprehensive ERP system construction, since a comprehensive reform of its financial management, strategic management, decision-making processes, which resulted in the kindergarten had to face multiple conflicts, including ERP efficiency and rationality between contradictions, lower the quality of staff between ERP Advancement and contradictions, wide range of applications and data preparation work complicated contradictions among large.

\section{Kindergarten Financial Management Strategies based on ERP System}

\section{A. The Establishment of Financial Risk Notion}

Kindergarten should establish a correct concept of financial risk. While the financial risk management and liquidity kindergarten, operating funds, debt ratio, the debt burden, profitability and other issues closely related to the daily management of the kindergarten, but not blindly rely on ERP systems, while ignoring improve their financial management capabilities.

Successful implementation of ERP systems for kindergarten introduced a new management mode and method, but because of the ERP system is still not deep enough to grasp and comprehensive, so that there remain specific operation certain loopholes and shortcomings. In this paper, the status of financial management under the ERP kindergarten background depth discussions aimed to remind people in the full adoption of ERP systems but also potential risks has increased its presence in the financial professional quality alert. For a modern kindergarten, it must improve its risk awareness, improve ERP system to improve their management and oversight capacity.

\section{B. Improve the Quality of Financial Personnel Services}

Kindergarten deal with its financial staff regular training to improve their quality, so that financial personnel aware of their responsibilities is not limited to accounting, also has oversight and guidance functions. ERP systems can bring many conveniences to kindergarten internal control. Financial officers have a responsibility to make the system play a real, effective role in the kindergarten inside, in order to achieve the kindergarten information management. Traditionally, since the financial staff of the kindergarten does not have control over the assets, they can only passively to changes in asset accounting, and not the full range of assets and proactively manage and control the whole process. In the ERP system, the right to financial officers has to be further expand, by monitoring the real flow of goods and capital, within the purview of the kindergarten can internal production and all aspects of operations control and management. 


\section{Financial Supervision}

Kindergarten conduct a comprehensive ERP system, its financial oversight must keep pace ERP, which provides support for the construction of ERP. This is because, before the establishment of the ERP system, kindergarten and other internal bookkeeping accounting work can be completed by the financial sector alone, but after the introduction of ERP systems, financial sector must collect data for the individual departments and business integration and then prepare the financial reports. In addition, ERP system, with its high-tech and comprehensive system to build more sophisticated, rich data plane kindergarten and increase the amount of data to improve the breadth of sources. This makes the system updates and data synchronization occurs and business intelligence, reducing data input caused due to human error, thereby improving the accuracy and efficiency of financial supervision and accounting statements.

Data from various ERP systems-related business, and because the financial capacity of different business people are different, and the quality of information processing are different, so the kindergarten should strengthen the unity of the financial staff training to ensure the validity of data and accuracy, while the kindergarten should also strengthen the inspection of the data, thereby reducing the incidence of erroneous data.

\section{Strategies of the Kindergarten Budget Management based on ERP Environment}

\section{A. Establish A Budget Appraisal Management Platform based on One's Performance}

Kindergarten financial management should set clear management goals, giving some policy guidance for the daily operations of the financial management. The overall goal of decomposition by-year, monthly goals, and ERP systems can complete the goal-related factors manifested, thereby allowing managers to be targeted at the goals, improve work efficiency, facilitate the completion of goals. As the market is changing, inevitably there are many unpredictable factors, kindergarten real condition and results of operations and the beginning of the program is different. Kindergarten should be based on current data, in order to make the next budget period adjusted accordingly, so that it is more in line with the actual situation, which can make kindergarten budget management more flexible, so as to promote kindergarten management for further development and improvement.

\section{B. Improve the Function of the ERP Module}

Kindergarten should improve some modules ERP system. For example, the kindergarten in the Device Manager does not have the credentials header text, and accordingly, it generates a line item is also a lack of text content. This leads to financial officers at the audit, could not verify the specific details, thus increasing the difficulty of the audit. In addition, it also makes financial officer unable to discover their financial details for errors, thereby increasing the financial risk. The best proof text automatically generated by a single generation equipment repair, improve the general ledger inquiry system.

\section{Simplified System Query Interface}

As the ERP system query operation is more complex, the need for better operational capability and capacity to understand the system, which for the kindergarten's leadership, it is a great challenge, it takes a lot of energy and time. Therefore, the kindergarten must be improved and updated ERP system, simplify the query operation process, making it easier for managers to grasp, to meet the needs of its decision-making. 


\section{Compensate for the Limitations of ERP Business Functions}

ERP systems through powerful, kindergartens departments can achieve timely exchange of information, reduce information communication barrier, so that contact between the module and the module closer. However, it is precisely because the relationship between the module and the module closer, the information a module error occurs it will directly affect the validity of the other modules of information, so, in the implementation of ERP systems, in order to ensure the correct data for each entry sex, kindergartens must increase data verification and supervision.

However, due to technical problems, ERP system still has some drawbacks, and does not approve all the operations within the system. Due to the limitations of manpower and cost of capital kindergarten, makes it impossible to conduct a comprehensive management and control of the entire business, which makes the system there are still some risks, we must rely on other means of redress. Due to lack of operator training, resulting in its understanding of the ERP system is not deep enough, and hindered efforts to simplify and optimize certain operations and efficiency. So, kindergarten managers must strengthen the training of operating personnel and the overall supervision of their work, thereby improving data accuracy, reducing the likelihood of occurrence of financial risk.

\section{E. Data Standardization}

For the construction of kindergartens, ERP systems should also improve their standardized management awareness, so as to the true concept of ERP and data technology. It is the key to a take comprehensive internal management of the kindergarten. Through the multiple aspects of information code, data sources, technical specifications, information technology platform to standardize management can improve the effectiveness of ERP systems. Kindergarten in building the ERP system at the same time, we should focus on improving its data standardization capabilities. The ability to successfully implement data standardization will directly affect the success or failure of ERP system. Therefore, the kindergarten should be unbiased, error-free operation of the system standardization. However, in practice the kindergarten, especially when the system is just on the line, due to lack of relevant experience, there are still many deficiencies on kindergarten standardization.

\section{Conclusion}

With the update of financial management theory of modern management, when kindergarten is currently conducting financial management, we should pay more attention to maximize their interests and make staff fully aware of the value of financial management in their daily work. In addition, the kindergarten should take a strategic management tool to achieve high returns and security assets from the perspective of the value chain, thereby enhance the core competitiveness of the kindergarten.

\section{Acknowledgements}

Project: 2015 Shaanxi Department of Education Research Project (No. 15JK1171) "Xi'an Kindergarten Financial Management and Strategic Research under ERP Environment" Initial Results

Project: 2015 Annual Shaanxi (Colleges and Universities) Philosophy and Social Science Research Base-Preschool Education Research and Development Center Project" Research of Public Kindergartens Internal Control based on COSO Framework" (No. JD2015S05) Initial Results 


\section{REFERENCE:}

[1] Jame R. Mcguigan. Managerial Economics Applications, Strategy, And Tactics[M].12th Ed. Mason: Cengage Learning, 2011.

[2] John L. Thompson. Lead With Vision: Manage The Strategic Challenge [M]. 1sted. Intl Thomson Business Press, 1997.

[3] Ralph E. Steuer. Multiple Criteria Optimization: Theory, Computation, And Application [M]. Wiley, 1996.

[4] Stephen Ross. Corporate Finance [M]. 9thed. New York: Mcgraw Hill, 2009. 